\title{
Combining salicylate and enalapril in patients with coronary artery disease and heart failure
}

L H B Baur, J J Schipperheyn, A van der Laarse, J H M Souverijn, M Frölich, A de Groot, P J Voogd, T F F P Vroom, V Manger Cats, M J N C Keirse, A V G Bruschke

\begin{abstract}
Objective-To study the effects of adding a salicylate to the angiotensin converting enzyme inhibitor enalapril in patients with heart failure due to coronary artery disease.

Design-Double blind, crossover study for three days in hospital followed by an extended similar study outside hospital over two months of once daily enalapril plus salicylate and enalapril plus placebo. Setting-Tertiary referral centre.

of enalapril in patients with heart failure by de-unloading the ventricle. Like other effects induced by bradykinin significant de-unloading occurs in only a minority of the patients. In the presence of enalapril, however, salicylate will probably not be as effective as expected in reducing reinfarction risk, because enalapril already reduces thromboxane $A_{2}$ synthesis effectively in patients with heart failure and no further reduction by salicylate was found.
\end{abstract}

Patients-20 patients with heart failure due to myocardial infarction (New York Heart Association class II or III) and an ejection fraction less than $0 \cdot 40$. Twelve patients completed the two parts of the study. Main outcome measures-Blood pressure, plasma converting enzyme activity; plasma angiotensin II and noradrenaline concentrations; excretion of metabolites of renal and systemic prostanoids.

Results-The unloading effect of first and second dose of enalapril in the morning lasted only during the day; in the extended study it lasted 24 hours because of the drug's accumulation. Converting enzyme inhibitors attenuate the breakdown of bradykinin and therefore enhance prostaglandin $E_{2}$ synthesis mediated by bradykinin. Evidence was found of such a prostaglandin $E_{2}$ mediated contribution to ventricular unloading by enalapril, which was blocked by salicylate. The contribution, however, was small and variable, and salicylate addition had on average no significant de-unloading effect during the day. Unloading was abolished in only three of the 20 patients in the short term study and in one of the 12 in the extended study. At night, when other effects of enalapril on blood pressure had waned and the bradykinin induced effect persisted, salicylate significantly reduced the remaining small unloading effect. No effect was seen of salicylate addition on reversal of remodelling. Enalapril reduced angiotensin II induced synthesis of systemic and renal prostaglandin $I_{2}$ and thromboxane $A_{2}$, initially only during the day, but later also at night. It thereby masked suppression of thromboxane $A_{2}$ synthesis by salicylate, which is the effect to which reinfarct prevention by salicylate is attributed.

Conclusion-The risk is low that salicylate will substantially reduce the benefit
(Br Heart f 1995;73:227-236)

Keywords: angiotensin converting enzyme inhibition; prostaglandin; heart failure; prevention of reinfarction

Treatment with an angiotensin converting enzyme inhibitor is indicated in patients with heart failure who have an ejection fraction of less than $0 \cdot 40$, irrespective of their symptoms. Enalapril was the first converting enzyme inhibitor to be shown to reduce mortality and delay progression from mild to severe congestive failure. ${ }^{12}$ In patients who survived a myocardial infarction, treatment with a salicylate once daily and in a low dose reduced the reinfarction rate and mortality. ${ }^{34}$ As converting enzyme inhibitors act differently from salicylates, it seems reasonable to expect that patients who survive an infarction and have a low ejection fraction will benefit more from taking the two drugs than from taking only one.

The beneficial action of converting enzyme inhibitors in heart failure is attributed to unloading the ventricle without undue sympathetic stimulation of the heart and to reversing, or at least retarding, the progression of dilatation and hypertrophy. The unloading effect of converting enzyme inhibitors is considered to be partly due to an increased production of vasodilating prostaglandins. ${ }^{56}$ This production might therefore be severely reduced if converting enzyme inhibitors are combined with non-steroidal anti-inflammatory drugs. ${ }^{7}$ Evidence in favour of the existence of such a "de-unloading" effect in patients with heart failure was reported recently-adding salicylate to enalapril raised arterial and left ventricular filling pressure in patients with heart failure. ${ }^{8}$ It is by no means clear, however, to what extent ventricular unloading by converting enzyme inhibitors is attributable to increased prostanoid production and, if so, to what extent a low dose of a salicylate will reduce the effect. 
The renin-angiotensin system also affects the synthesis of prostanoids in the systemic and renal circulation. Angiotensin converting enzyme is identical to kininase II, which breaks down bradykinin. Therefore, converting enzyme inhibitors increase endogenous bradykinin concentrations, increasing the release of vasodilating prostaglandin $\mathrm{I}_{2}$ and $\mathrm{E}_{2}$ into the systemic circulation. ${ }^{59}$ Such stimulation of prostaglandin synthesis contributed to the antihypertensive and unloading action of converting enzyme inhibitors. ${ }^{6710}$ Angiotensin II activates production of the vasodilating prostanoids prostaglandin $\mathrm{I}_{2}$ and prostaglandin $\mathrm{E}_{2}$ in the kidney, ${ }^{11-13}$ which is the mechanism underlying activation of renal prostaglandin synthesis by diuretics. ${ }^{14}$ Converting enzyme inhibitors are therefore expected to reduce rather than enhance renal prostanoid synthesis. Occasionally, however, renal prostanoid synthesis has been stimulated (albeit indirectly) rather than suppressed by converting enzyme inhibitors. This is because converting enzyme inhibition potentiates the conversion of angiotensin I into angiotensin(1-7), which like angiotensin II stimulates the synthesis of vasodilating renal prostanoids. ${ }^{15}$ Angiotensin II induced contractions of isolated blood vessels are attenuated by indomethacin and by blockade of thromboxane receptors, suggesting the existence of a thromboxane mediated amplification of angiotensin II induced vasoconstriction. ${ }^{16}$ Converting enzyme inhibitors and salicylate can both be expected to reduce such a thromboxane mediated effect.

In view of the conflicting effects that converting enzyme inhibitors may have on systemic and renal prostanoid synthesis, the de-unloading effect of salicylate in patients treated with a converting enzyme inhibitor is probably less consistent than suggested previously. ${ }^{8}$ It may depend on dosage and relative timing of the two drugs, and it may vary from patient to patient. Therefore, to interpret results of studies of the addition of a nonsteroidal anti-inflammatory drug to a converting enzyme inhibitor, the effects of drug treatment on haemodynamic parameters and on renal and systemic prostanoid synthesis must be measured.

To obtain such data we studied the effects of a single dose of salicylate on the day after starting enalapril in 20 patients with coronary artery disease and severe cardiac failure. To find out whether salicylate addition exerted any influence on the long term effects of the converting enzyme inhibitor on haemodynamic load and geometry of the left ventricle, we extended the study for four weeks.

\section{Patients and methods}

PATIENTS

Participants in the study were recruited among patients admitted to the hospital for clinical evaluation of cardiac pump function and for instigation of medical treatment for heart failure. They were asked to participate if they fulfilled the entrance criteria and had none of the exclusion criteria. Twenty patients (18 men, two women) entered the study; their ages ranged from 23 to 70 years (mean 60). They all had coronary artery disease and cardiac failure (New York Heart Association class II or III) as a result of one, or occasionally several, myocardial infarctions. Left ventricular ejection fractions were less than 0.40 (mean 0.25). Exclusion criteria were overt decompensation, unstable angina, recent infarction, hypotension, albuminuria, a serum creatinine concentration above $150 \mu \mathrm{mol} / 1$, renal artery stenosis, peptic ulcer or congenital heart disease, and the regular use of non-steroidal anti-inflammatory drugs, corticosteroids, or immunosuppressive drugs. One patient was withdrawn because of severe hypotension after the first dose of enalapril.

The study lasted three days, during which the patients remained in hospital. Immediately thereafter, they all entered into an eight weeks extension of the study outside hospital, for which they were scheduled to return twice to the outpatient clinic for extensive evaluation. Participation in the extension of the study was terminated if there were major complications, such as myocardial infarction, unstable angina, or decompensation, or if the patient's physician found it necessary to substantially change the dose of either the diuretic or the converting enzyme inhibitor. Eight patients were withdrawn: five because of major changes in drug treatment and three for other reasons. One was withdrawn because of unstable angina requiring an acute bypass operation, the second because of the detection of a malignant tumour, and the last at his own request. Twelve patients thus completed the extended study. Before entry all patients gave their informed consent. The study was approved by the medical ethics committee of the hospital.

\section{STUDY DESIGN}

The study was designed as a double blind, crossover trial comparing salicylate with placebo, both added to a converting enzyme inhibitor. The order of placebo and active treatment was not randomised and all patients first received a placebo followed by active treatment the next day. However, neither patients nor the medical and nursing staff involved were informed about the order in which the agents were given. All blood and urine samples were analysed by laboratory staff blinded to patients' identity and the order of sampling. Patients remained in hospital for at least three days, the first day taking no study medication to obtain baseline values, the second day taking enalapril and placebo, and the third day taking enalapril plus salicylate.

During the extension of the study, patients were also unaware that first a placebo was added for four weeks, followed by salicylate for another four weeks. The house staff involved in measuring blood pressure and taking samples were also not informed. The investigator who performed the echographic studies had to know the order of treatment, however. 


\section{DRUG TREATMENT}

Ten patients were taking a converting enzyme inhibitor before admission. This treatment was stopped at least two days before the study. All other treatments were continued. Every patient used phenprocoumon as an anticoagulant. Thirteen patients took frusemide, three digoxin, four a long acting nitrate, four a calcium antagonist, and two patients an antiarrhythmic drug. To obtain baseline values no converting enzyme inhibitor was given on the first day of the study. From the second day onwards, enalapril was given in a dose that was kept fixed for the duration of the study; $5 \mathrm{mg}$ once daily to five patients and $10 \mathrm{mg}$ once daily to 15 , the dose depending on the patients' renal function. A placebo was added to the first dose of enalapril, the next day $300 \mathrm{mg}$ of carbaspirin calcium, a complex of urea and calcium acetylsalicylate, was added, which corresponds to $250 \mathrm{mg}$ aspirin. The same dose regimen was used in the extension of the study.

\section{MEASUREMENTS}

Echocardiography was performed at the beginning of the study and after four and eight weeks. A Vingmed CFM-750 echocardiograph (Trondheim, Norway) was used, linked to an Apple-Macintosh computer for data analysis. Exercise tests were performed on a bicycle ergometer equipped with an Oxycon $\mathrm{V}$ system for measuring oxygen consumption (Mijnhardt, Bunnik, The Netherlands). Blood pressure was measured before and five and 24 hours after treatment with an automatic device that took 10 readings within 30 minutes (Accutor, Datascope, Montvale, NJ, USA). From the readings of systolic and diastolic pressures, a mean pressure was calculated by adding one third of the difference to the value of the diastolic pressure. All values given are means of 10 consecutive mean pressures. Immediately after the pressure recordings, blood samples were taken to determine plasma concentrations of angiotensin II, noradrenaline, sodium, potassium, and creatinine; plasma activities of angiotensin converting enzyme; and plasma osmolality.

Blood samples were taken when the patients were supine and had been at rest for at least two hours. Samples for angiotensin II measurements, collected in tubes containing disodium edetate and phenanthroline, were put on ice immediately and centrifuged as soon as possible in a precooled centrifuge; the plasma was subsequently stored at $-70^{\circ} \mathrm{C}$. Angiotensin II was purified using solid phase extraction with SEP-Pak C-18 cartridges (Waters Associates, Milford, MA, USA); it was measured by radioimmunoassay using a polyclonal antibody (Ang II-AS No 923) produced by Hoffmann-LaRoche (Basle, Switzerland). Plasma angiotensin converting enzyme activity was measured by a colorimetric method with a test kit (Fuji Rebio, Tokyo, Japan). Noradrenaline was assayed by an electrochemical detection method after purifi- cation with a high pressure liquid chromatography technique. Urine was collected from 2300 to 0800 and, during the first three days in hospital, also from 0900 to 1300.

Data were collected after four and eight weeks during a visit to the outpatient clinic, where patients brought their urine collected from 2300 to 0800 . From urinary concentrations of sodium, creatinine, and prostanoid metabolites, the sodium excretion, free water production, and creatinine clearance were calculated. Male patients were asked to defer ejaculation. A sample of the urine collected $(50 \mathrm{ml})$ was centrifuged in a precooled centrifuge and subsequently stored at $-70^{\circ} \mathrm{C}$ until further analysis. Concentrations of the prostanoid metabolites thromboxane $\mathrm{B}_{2}$ and 6-ketoprostaglandin $\mathrm{F}_{1 a}$ and of its dinor equivalents were measured using high pressure liquid chromatography and radioimmunoassay. The techniques used to measure prostanoid metabolites in the urine have been described elsewhere. ${ }^{1718}$ Excretion of thromboxane $B_{2}$ and of 6-ketoprostaglandin $\mathrm{F}_{1 \alpha}$ predominantly reflects the renal biosynthesis of thromboxane $A_{2}$ and prostaglandin $I_{2}$ respectively, while the excretion of the dinor metabolites reflects systemic synthesis. ${ }^{19}$

\section{STATISTICAL ANALYSIS}

Results are reported as means and standard deviations. Results were compared using analysis of variance, $t$ tests with Bonferroni correction, and paired $t$ tests when appropriate. Differences were considered to be significant at $P<0.05$.

\section{Results}

RENIN-ANGIOTENSIN SYSTEM

Without treatment plasma converting enzyme activity was high in all patients $(39 \cdot 3(17 \cdot 8)$ $\mathrm{U} / \mathrm{l})$ and remained remarkably constant during the day, the difference between values in the morning and afternoon being less than $0.3 \%$ (figure 1 ). Five hours after the first dose of enalapril, plasma converting enzyme activity had dropped to $9 \cdot 1(7 \cdot 6) \mathrm{U} / \mathrm{l}$. The next morning before treatment it had risen to $16 \cdot 1$ $(12 \cdot 3)$ U/1. Five hours after the second dose it was $8 \cdot 2(9 \cdot 1) \mathrm{U} / 1$, and it subsequently increased to $18 \cdot 8(13 \cdot 0) \mathrm{U} / 1$ the next morning. Enalapril in a rather low dose and given once daily reduced plasma converting enzyme activity to $25 \%$ of pretreatment values around noon and to $50 \%$ early the next morning.

Before treatment plasma angiotensin II concentrations were high in almost all patients and, unlike plasma converting enzyme activities, they showed a circadian variation. Mean baseline values increased from $47 \cdot 0(31 \cdot 7)$ $\mathrm{pmol} / \mathrm{l}$ early in the morning to $64.5(48.0)$ $\mathrm{pmol} / 1$ in the afternoon $(P<0.01)$. Despite the steep fall of plasma converting enzyme activity after the first dose of enalapril, the mean angiotensin II concentration measured at noon (five hours after taking enalapril) was only slightly and insignificantly lower than the day before $(58 \cdot 7(46 \cdot 6) \mathrm{pmol} / \mathrm{l})$. Two groups of patients (I and II) could be distinguished 
Figure 1 Mean blood pressure, plasma noradrenaline and angiotensin II concentrations, and plasma converting enzyme activity ( $A C E$ ) at midday (open bars) and early next morning (hatched bars). Vertical lines show SD. Early morning blood pressure after enalapril and salicylate was significantly higher than after enalapril and placebo. Plasma converting enzyme activity and blood pressure fell immediately after enalapril while the change in noradrenaline and angiotensin II concentrations were delayed.
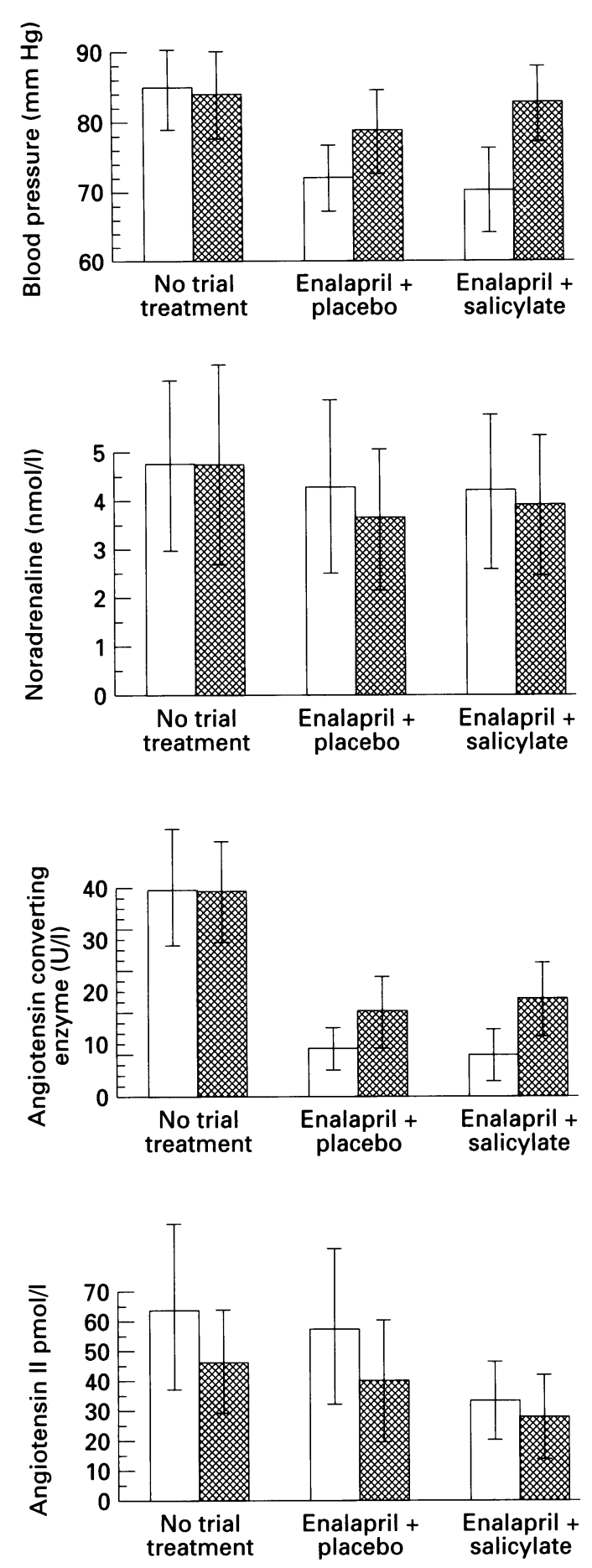

on the basis of their plasma angiotensin II concentration after the first dose of enalapril. Angiotensin II concentrations in the nine patients in group I did not fall. Values were on average up to $53 \%$ higher than those the day before; the mean value at noon increased from $49.0(27.9) \mathrm{pmol} / 1$ to $75 \cdot 1(52.6) \mathrm{pmol} / \mathrm{l}(\mathrm{P}<$ $0 \cdot 03$ ). Group II comprised 11 patients; their midday plasma angiotensin II concentrations were lower than the day before and the mean value for this group dropped from $82.6(58.0)$ $\mathrm{pmol} / 1$ to $47.7(39.5) \mathrm{pmol} / 1 \quad(\mathrm{P}<0.01)$. Groups I and II did not differ with respect to dose of enalapril or previous use of a converting enzyme inhibitor. Blood pressures in the two groups did not differ either, but pretreatment angiotensin II concentrations in group
II were 1.7 times higher than those in group I (NS) and corresponding noradrenaline concentrations were as much as twice as high ( $P$ $<0.05)$. The plasma converting enzyme activity before treatment was similar in both groups, but after treatment patients in group I had a plasma converting enzyme activity more than twice as high as that of patients in group II $(P<0.05)$. This indicated that although the renin-angiotensin system and sympathetic nervous system of patients in group II was initially more strongly activated, their converting enzyme activity was more effectively inhibited.

On the second day of treatment four patients still had plasma angiotensin II concentrations at noon that were slightly above their respective pretreatment values, but the mean values in groups I and II were no longer significantly different and the mean value for the whole group fell to $59 \%$ of its pretreatment mean value $(37.9(24.4) \mathrm{pmol} / \mathrm{l})$.

\section{BLOOD PRESSURE}

Average mean blood pressures in the morning and at noon were initially $84.2(11.0) \mathrm{mm} \mathrm{Hg}$ and $85.2(10.6) \mathrm{mm} \mathrm{Hg}$ (figure 1). After the first dose of enalapril mean blood pressure fell to $72 \cdot 2(9 \cdot 4) \mathrm{mm} \mathrm{Hg}$ at noon, which was 13 $\mathrm{mm} \mathrm{Hg}$ lower than on the day before; it subsequently increased to $79 \cdot 2(10 \cdot 6) \mathrm{mm} \mathrm{Hg}$ early next morning. After the second dose of enalapril, combined with salicylate, pressure fell to $70.5(10.7) \mathrm{mm} \mathrm{Hg}$ at noon, which was not significantly different from the pressure on the first day of treatment after enalapril alone. Thus, at first sight, salicylate did not seem to reverse the unloading effect of enalapril. In three patients the unloading effect of enalapril was completely abolished and their blood pressure was on average almost $15 \mathrm{~mm} \mathrm{Hg}$ higher than the day before. Blood pressure after enalapril and salicylate was on average $2.8 \mathrm{~mm} \mathrm{Hg}$ higher than after enalapril and placebo in another seven patients (NS). Thus, salicylate reversed the unloading effect of enalapril in three out of 20 cases and may have attenuated the effect in a few others.

After salicylate blood pressure increased overnight to $83.3(9.9) \mathrm{mm} \mathrm{Hg}$ early in the morning, which was significantly higher than the corresponding value after enalapril without salicylate $(P<0.05)$. During the night, when the effect of the enalapril had waned, salicylate thus came close to abolishing the remaining unloading effect of enalapril if it was still present.

\section{RENAL FUNCTION}

Creatinine clearance before treatment showed circadian variation $\left(114(72) \mathrm{ml} / \mathrm{min} / 1.73 \mathrm{~m}^{2}\right.$ in the morning $v 59(29) \mathrm{ml} / \mathrm{min} / 1 \cdot 73 \mathrm{~m}^{2}$ during the night). Daytime clearance fell to 80 (63) $\mathrm{ml} / \mathrm{min} / 1.73 \mathrm{~m}^{2}$ after enalapril and placebo and to $79(60) \mathrm{ml} / \mathrm{min} / 1.73 \mathrm{~m}^{2}$ after enalapril and salicylate. Creatinine clearances measured during the night were unaffected, being $59(25) \mathrm{ml} / \mathrm{min} / 1 \cdot 73 \mathrm{~m}^{2}$ after the first day of treatment and $57(34) \mathrm{ml} / \mathrm{min} / 1.73 \mathrm{~m}^{2}$ after the second. All patients while in hospital 
Figure 2 Excretion of systemic (dinor) and renal prostanoids during the day (open bars) and night (hatched bars). Vertical lines show SD. Enalapril did not affect excretion at night but during the day excretion of all metabolites was reduced. Salicylate significantly reduced thromboxane $B_{2}$ and dinor-thromboxane $B_{2}$ excretion but only at night.
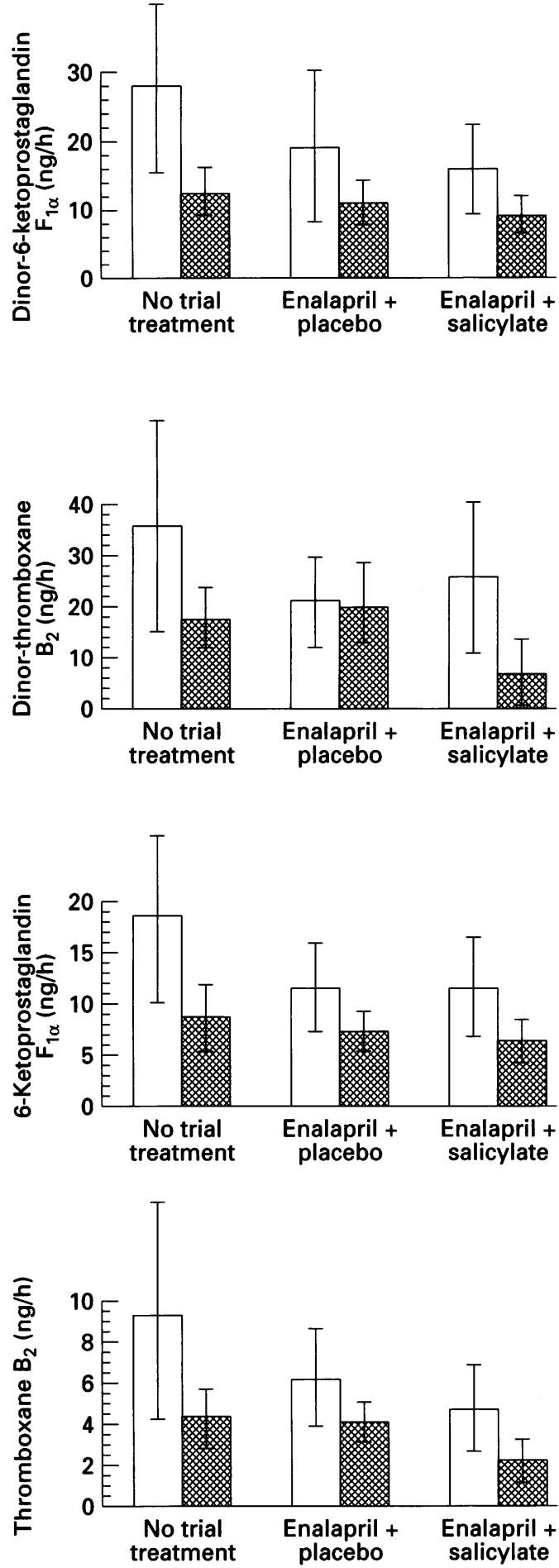

ate a low salt diet (sodium chloride $<23$ $\mathrm{mmol} /$ day). Salt excretion at baseline was slightly higher in the morning than during the night. Daytime salt excretion increased significantly after enalapril and after enalapril plus salicylate. Free water production showed no circadian variation. It increased by $48 \%$ after the first dose of enalapril and by $32 \%$ the next day after combined treatment.

\section{SYMPATHETIC NERVOUS SYSTEM}

Plasma noradrenaline concentrations before drug treatment were raised in most patients. The mean values before treatment were 4.78 (3.92) $\mathrm{nmol} / \mathrm{l}$ in the morning and $4.78(3.28)$ $\mathrm{nmol} / \mathrm{l}$ at noon (figure 1 ). Concentrations tended to fall over the next two days, but the changes were small and not significant. The concentration was $4.34(3.29) \mathrm{nmol} / \mathrm{l}$ five hours after the first dose of enalapril and 3.69 $(2 \cdot 74) \mathrm{nmol} / \mathrm{l}$ the next morning. After enalapril combined with salicylate it remained at $4.26(3.06) \mathrm{nmol} / \mathrm{l}$ in the afternoon and at $3.98(2.66) \mathrm{nmol} / \mathrm{l}$ the next morning.

\section{PROSTANOIDS}

Daytime excretion of the dinor metabolites of systemically produced prostanoids was about twice as high as that during the night (figure 2). The excretion of dinor-6-ketoprostaglandin $\mathrm{F}_{1 \alpha}$ was $27.3(23.9) \mathrm{ng} / \mathrm{h}$ during the morning and $12 \cdot 3(6 \cdot 6) \mathrm{ng} / \mathrm{h}$ at night; corresponding values for dinor-thromboxane $B_{2}$ were $34.9(40.0) \mathrm{ng} / \mathrm{h}$ and $17.2(11.8) \mathrm{ng} / \mathrm{h}$. The ratio of prostaglandin $F_{1 \alpha}$ to thromboxane $B_{2}$ concentration were 0.78 and 0.71 , which is below the normal value of about 1 . Morning excretion of dinor-6-ketoprostaglandin $F_{1 \alpha}$ and dinor-thromboxane $B_{2}$ dropped significantly after the first dose of enalapril to $18.6(21.3) \mathrm{ng} / \mathrm{h}$ and $20.8(17.2)$ $\mathrm{ng} / \mathrm{h}$, respectively; their ratio thus increased to $0 \cdot 89$. The figures were not significantly influenced by adding salicylate $(15 \cdot 7(12 \cdot 6)$ and $25.6(28.9) \mathrm{nmol} / \mathrm{h})$. In contrast, the night time excretion of dinor-thromboxane $B_{2}$, which was not influenced by the converting enzyme inhibitor, dropped sharply after addition of the salicylate from $19.9(15.4) \mathrm{ng} / \mathrm{h}$ to $7.3(13 \cdot 2) \mathrm{ng} / \mathrm{h}$; excretion of dinor-6-ketoprostaglandin $F_{1 \alpha}$ was not changed. As a result, the ratio of prostaglandin $F_{1 a}$ to thromboxane $\mathrm{B}_{2}$ concentration increased to $1 \cdot 26$, which is distinctly higher than normal.

The effects of the converting enzyme inhibitor and the salicylate on the excretion of the renal prostanoids were quite similar to those on the excretion of systemic prostanoids. Renal prostanoid excretion showed circadian variation like that of the systemic equivalents, but the ratio of prostaglandin $F_{1 \alpha}$ to thromboxane $B_{2}$ concentration was 1.9 in the morning and 2.0 at night, which is about twice the normal value. Excretion of 6-ketoprostaglandin $F_{1 \alpha}$ was $18 \cdot 3$ $(16.4) \mathrm{ng} / \mathrm{h}$ in the morning and $8.6(6.3) \mathrm{ng} / \mathrm{h}$ during the night. Corresponding values for thromboxane $B_{2}$ were $9.5(10.4) \mathrm{ng} / \mathrm{h}$ and 4.3 $(2 \cdot 8) \mathrm{ng} / \mathrm{h}$ respectively. As for the systemic prostanoids, the converting enzyme inhibitor had no effect on excretion during the night, but it reduced both 6-ketoprostaglandin $\mathrm{F}_{1 \alpha}$ and thromboxane $B_{2}$ excretion during the day to $11.5(8.6) \mathrm{ng} / \mathrm{h}$ and $6.3(4.7) \mathrm{ng} / \mathrm{h}$, respectively. The addition of salicylate had no additional effect and left the daytime excretions at $11.5(9 \cdot 3) \mathrm{ng} / \mathrm{h}$ and $4.9(4 \cdot 1) \mathrm{ng} / \mathrm{h}$. Similar to what was found for the systemic prostanoids, salicylate had no effect on daytime excretion of prostanoids, while during the night only the excretion of thromboxane $B_{2}$ was reduced, from $4.2(2.0)$ to $2.4(2.2) \mathrm{ng} / \mathrm{h}$. The night time excretion of 6-ketoprostaglandin $F_{1 \alpha}$ was $7 \cdot 3(3 \cdot 7) \mathrm{ng} / \mathrm{h}$ after enalapril and placebo and $6.6(4.4) \mathrm{ng} / \mathrm{h}$ after enalapril and salicylate (NS). 
Figure 3 Mean blood pressure, plasma angiotensin II and noradrenaline concentrations, and plasma converting enzyme activity before the trial and after four weeks of enalapril and placebo and four weeks of enalapril and salicylate. Vertical lines show $S D$. The addition of salicylate had no effect.
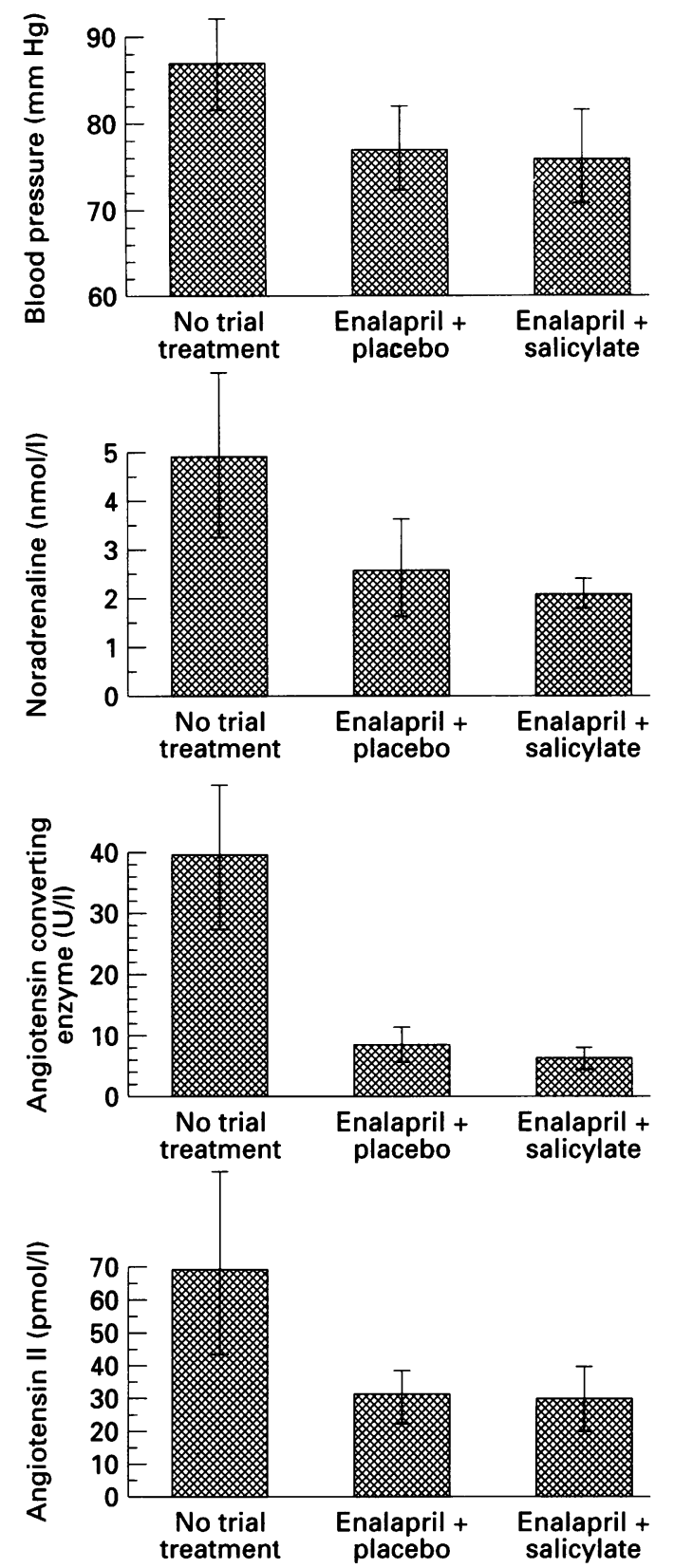

\section{EXTENDED STUDY}

Converting enzyme inhibitor and salicylate showed a consistent effect in the 12 patients who completed the extended study. Blood pressure in the early afternoon fell from 86.8 $(10 \cdot 3) \mathrm{mm} \mathrm{Hg}$ to $76.7(9.7) \mathrm{mm} \mathrm{Hg}$ after four weeks and to $75.4(10.5) \mathrm{mm} \mathrm{Hg}$ after eight weeks (figure 3). This means that, as in the short term study, there was on average no reversal of unloading. Unloading was, however, completely abolished in one patient and was partly, but not significantly, reversed in three others.

Plasma converting enzyme activity fell from $39.6(23.0) \mathrm{pmol} / \mathrm{l}$ at baseline to $8.3(5.5)$ $\mathrm{pmol} / \mathrm{l}$ and $6.0(3.4) \mathrm{pmol} / \mathrm{l}$ after four and eight weeks respectively (figure 3 ). Plasma angiotensin II and noradrenaline concentrations, which showed either inconsistent changes or none at all after the first dose of enalapril, were both lowered after eight weeks of enalapril treatment to about $50 \%$ of pretreatment values, with no changes after adding salicylate. Plasma angiotensin II concentration fell from $69.6(53.2) \mathrm{pmol} / 1$ to 30.5 $(15 \cdot 1) \mathrm{pmol} / \mathrm{l}$ after four weeks and to $29 \cdot 2$ (19.5) $\mathrm{pmol} / \mathrm{l}$ after eight weeks. Plasma noradrenaline concentration fell from $4.91(3 \cdot 22)$ $\mathrm{nmol} / 1$ to $2.57(1.90) \mathrm{nmol} / \mathrm{l}$ after four weeks and to $2.05(0.62) \mathrm{nmol} / \mathrm{l}$ after eight weeks.

Creatinine clearance during the night, which was not affected by the converting enzyme inhibitor during the short term study, was also not changed significantly during the extended study. Although salt secretion and free water production were increased during the first two days of enalapril treatment, they returned to their pretreatment values after four and eight weeks, which suggests that converting enzyme inhibitor treatment led to a transient negative salt and water balance.

The night time excretion of dinor-6-ketoprostaglandin $F_{1 a}$, which was not significantly influenced by enalapril during the short term study, dropped significantly from $12 \cdot 0(6 \cdot 2)$ $\mathrm{ng} / \mathrm{h}$ to $8.7(4.0) \mathrm{ng} / \mathrm{h}$ after four weeks of taking enalapril and placebo and to $7 \cdot 4(4 \cdot 7) \mathrm{ng} / \mathrm{h}$ after another four weeks of taking enalapril and salicylate (figure 4). Corresponding values for dinor-thromboxane $B_{2}$ were 15.9 $(11.2) \mathrm{ng} / \mathrm{h}$ initially, and $9.7(7 \cdot 7) \mathrm{ng} / \mathrm{h}$ after four weeks. There was no additional fall after four weeks of taking enalapril and salicylate, night time excretion remaining at $9 \cdot 1(7 \cdot 9) \mathrm{ng} / \mathrm{h}$.

The metabolites of renal prostanoids behaved in the same way (figure 4). There was no significant effect on night time excretion during the short term study, but 6-ketoprostaglandin $F_{1 a}$ excretion fell significantly from $8.4(4.0) \mathrm{ng} / \mathrm{h}$ to $4.9(2 \cdot 3) \mathrm{ng} / \mathrm{h}$ after four weeks of enalapril alone and to $5 \cdot 0(3 \cdot 7) \mathrm{ng} / \mathrm{h}$ after four weeks of enalapril combined with salicylate. Thromboxane $\mathbf{B}_{2}$ excretion overnight fell from $4.2(2.4) \mathrm{ng} / \mathrm{h}$ initially to $3.5(1.7) \mathrm{ng} / \mathrm{h}$ after four weeks; it also showed no additional decrease when salicylate was added, remaining at $3 \cdot 3(2 \cdot 6) \mathrm{ng} / \mathrm{h}$.

Treatment with enalapril reduced cardiac mass index from $135 \cdot 1(46 \cdot 2) \mathrm{g} / \mathrm{m}^{2}$ initially to $130 \cdot 1(46 \cdot 2)$ after four weeks (NS) and 120.1 $(53.6) \mathrm{g} / \mathrm{m}^{2}$ after eight weeks $(P<0.05)$. The end diastolic volume index of the left ventricle was $102.8(28.3) \mathrm{ml} / \mathrm{m}^{2}$ at baseline, 99.6 $(27.4) \mathrm{ml} / \mathrm{m}^{2}$ after four weeks, and 101.8 $(28.3) \mathrm{ml} / \mathrm{m}^{2}$ after eight weeks (NS). Ejection fraction improved slightly, but not significantly, from $0.26(0.10)$ initially to 0.29 $(0 \cdot 10)$ after four weeks and $0.32(0 \cdot 10)$ after eight weeks. Maximal aerobic capacity increased significantly from 90 (34) W to 126 (62) W after four weeks, remaining unchanged at 127 (62) W after eight weeks. The maximal rate-pressure product increased significantly from $16.8(3.9)$ to 21.6 $(7 \cdot 5) \times 10^{3} \mathrm{~mm} \mathrm{Hg} / \mathrm{min}$ after four weeks and remained at $22.8(5.9) \times 10^{3} \mathrm{~mm} \mathrm{Hg} / \mathrm{min}$ after eight weeks. Maximal oxygen consumption increased significantly from $14 \cdot 1(4 \cdot 5)$ $\mathrm{ml} / \mathrm{min} / \mathrm{kg}$ to $19.6(7 \cdot 4) \mathrm{ml} / \mathrm{min} / \mathrm{kg}$ after four weeks, and remaining at exactly the same value after eight weeks. 
Figure 4 Overnight excretion of prostanoid metabolites before trial and after four weeks of enalapril and placebo and four weeks of enalapril and salicylate. Vertical lines show SD. Contrary to findings during the short term part of the study, enalapril reduced the night time excretion of all four metabolites, masking the inhibitory effect of salicylate on thromboxane $B_{2}$ excretion.
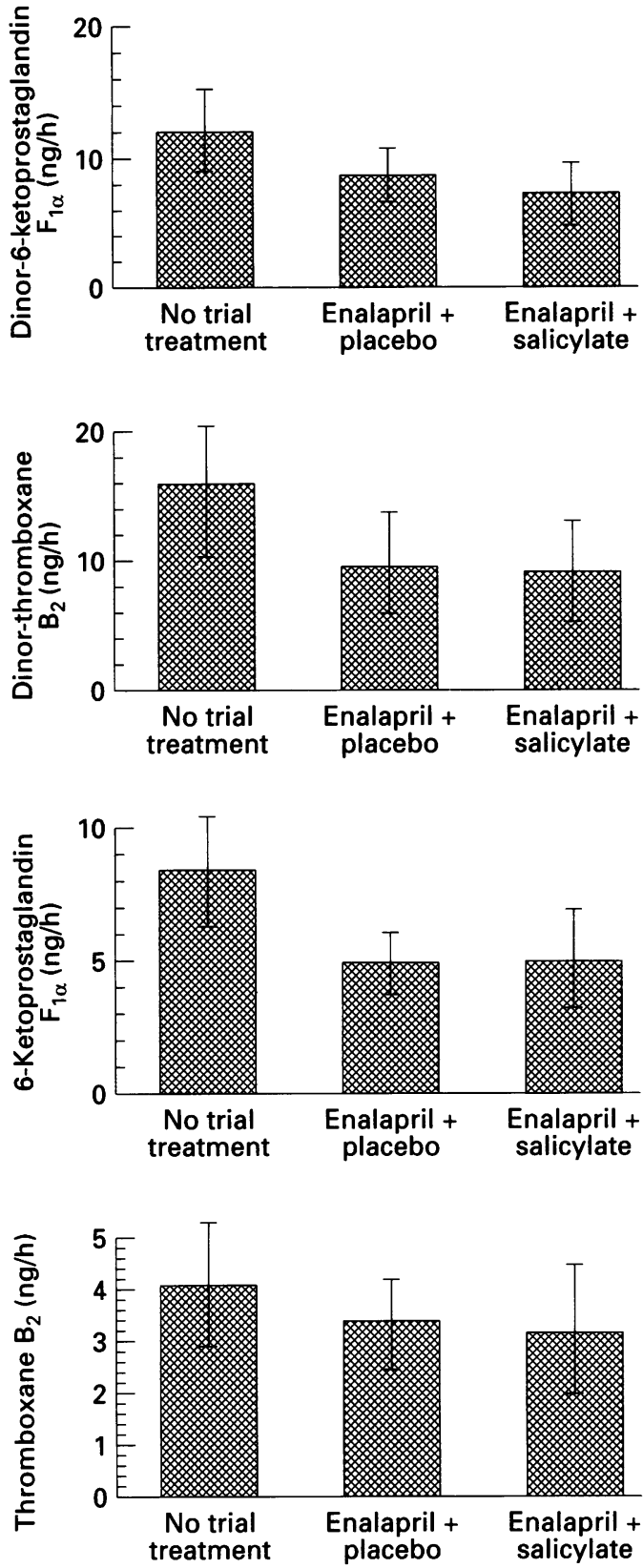

\section{Discussion}

All patients included in the study had cardiac failure and were eating a salt restricted diet; most of them used a diuretic. As a result, their renin-angiotensin and sympathetic nervous systems were strongly activated and plasma converting enzyme activity and plasma angiotensin II and noradrenaline concentrations were high. Five hours after the first dose of the converting enzyme inhibitor enalapril their blood pressure and plasma converting enzyme activity had dropped to values close to a new steady state. This was maintained during the extension of the study.

The fall in plasma angiotensin II and noradrenaline concentrations, however, developed much more slowly. After the first dose plasma angiotensin II concentrations decreased slightly in 11 patients and remained unchanged or even increased in nine. We noticed that the fall in blood pressure preceded the fall in blood concentration of angiotensin II and that blood pressures after converting enzyme inhibition did not correlate well with plasma angiotensin II concentrations. We initially hypothesised that the antihypertensive action of converting enzyme inhibitors is due mainly to raised circulating concentrations of vasodilating prostaglandins. ${ }^{61020}$ It is now recognised that plasma converting enzyme activity does not necessarily reflect activity of the angiotensin I converting ectoenzyme of elements within the vascular wall and deep inside the tissue. ${ }^{21}$ Angiotensin II that remains after converting enzyme inhibition depends on the converting enzyme activity expressed locally by tissue cells, the availability of converting enzyme inhibitor locally to inhibit that activity, and other factors such as the presence of a reactively increased concentration of angiotensin I and other proteinases that can convert angiotensin I. The blood pressure lowering effect of converting enzyme inhibition is mainly due to a suppression of the production-by vessel wall ectoenzymes-of angiotensin II acting locally on vascular smooth muscle cells. A comparatively high plasma concentration is maintained by escape of angiotensin II from tissue in which converting enzyme activity is incompletely suppressed or in which angiotensin II is produced by other proteinases.

To understand the paradoxical finding of a rise in plasma angiotensin II concentration after the first dose of converting enzyme inhibitor while blood pressure is lowered, it seems relevant that patients in whom this occurred had a considerably higher plasma converting enzyme activity after enalapril than had the others; their angiotensin II production was apparently not as effectively suppressed. When enalapril penetrated into the tissues the plasma angiotensin II concentration began to decrease. The mean for the whole group had dropped to $59 \%$ of baseline after the second dose of enalapril, although concentrations close to pretreatment values were still found in four patients. After four weeks, however, plasma angiotensin II concentration had diminished in all patients included in the extended study to a mean of $44 \%$ of baseline. Particularly when converting enzyme activity is only weakly inhibited, rising concentrations of angiotensin I can be expected to stimulate production of angiotensin II by tissue converting enzyme. This explains why converting enzyme inhibitors given once daily usually do not succeed in decreasing plasma angiotensin II concentrations for the full 24 hours. ${ }^{22}$ The plasma angiotensin II concentrations above baseline after the first dose were apparently not high enough to exert an appreciable effect on blood pressure. A temporary rise in angiotensin II concentration caused by stimulation of tissue converting enzyme by angiotensin I has been shown in isolated human myocardium. ${ }^{23}$ As angiotensin II has toxic effects on heart muscle, ${ }^{24}$ our findings suggest that converting enzyme inhibition soon after an infarction should be started cautiously when pump function is compromised. 
The fall in plasma noradrenaline concentration was slow and concurrent with that of plasma angiotensin II concentration. The noradrenaline in blood has escaped from tissues. In our study its production was probably stimulated by tissue angiotensin II, whose production was transiently stimulated after the first dose. In contrast to that of noradrenaline, the reduction in prostanoid production was not delayed and excretion of metabolites was suppressed immediately to new steady state values; it followed the course of the drop of blood pressure. Prostanoid synthesis may therefore be stimulated by the same angiotensin II derived from vessel walls that contributed to systemic vasoconstriction. Angiotensin II stimulates the liberation of arachidonic acid and subsequent formation of prostanoids in the endothelium. ${ }^{25}$ Our findings of a significant fall in the midday excretion of dinor-prostanoid after a single dose of enalapril in the morning and a slight increase in the ratio of dinor-6-ketoprostaglandin $\mathrm{F}_{1 a}$ to dinor-thromboxane $B_{2}$ concentration suggest that angiotensin II stimulates prostanoid synthesis-thromboxane $\mathrm{A}_{2}$ synthesis more than that of prostaglandin $I_{2}$. At least in our patients, angiotensin II tips the balance of prostanoid synthesis in favour of that of the vasoconstricting and thrombogenic thromboxane $A_{2}$, thereby amplifying its vasoconstricting effect. ${ }^{16}$

Our data agree with those from an earlier study in normal subjects which concluded that converting enzyme inhibitors stimulate synthesis of vasodilatory prostaglandins by inhibiting the breakdown of bradykinin by kininase II. ${ }^{5}$ In that study, as in ours, converting enzyme inhibition also did not raise the plasma concentrations of dinor-6-ketoprostaglandin $F_{1 \alpha}$ and dinor-thromboxane $B_{2}$, the metabolites of prostaglandin $I_{2}$ and thromboxane $\mathrm{A}_{2}$, but only those of the prostaglandin $\mathrm{E}_{2}$ metabolite prostaglandin $\mathrm{E}_{2}-\mathrm{M}$ -and then only when the renin-angiotensin system was first stimulated by restriction of sodium intake. ${ }^{5}$ Similar results were reported in a comparable study carried out in hypertensive subjects eating a salt restricted diet. ${ }^{6}$ In this study thromboxane $\mathrm{A}_{2}$ and prostaglandin $I_{2}$ synthesis were unaffected, but prostaglandin $E_{2}$ synthesis was increased and could be blocked in nine out of 10 patients by pretreatment with $25 \mathrm{mg}$ indomethacin four times a day, and in four out of eight others by $600 \mathrm{mg}$ aspirin four times a day. ${ }^{6}$ In one study in patients with heart failure, captopril induced a slight increase in plasma concentrations not only of prostaglandin $\mathrm{E}_{2}$ but also of 6-ketoprostaglandin $\mathrm{F}_{1 \alpha}$ from the kidney, and this could be blocked by pretreatment with 50 $\mathrm{mg}$ indomethacin. ${ }^{7} \mathrm{~A}$ more recent study in hypertensive subjects showed, however, that captopril prevented the rise in renal prostaglandin $I_{2}$ and prostaglandin $\mathrm{E}_{2}$ metabolite excretion that was induced by stimulating the renin-angiotensin system with frusemide.

Our results are inconclusive so far as prostaglandin $E_{2}$ is concerned. Data do not exclude a contribution of an enalapril medi- ated stimulation of prostaglandin $\mathrm{E}_{2}$ synthesis to the unloading effect of the converting enzyme inhibitor, as found for captopril, ${ }^{679}$ because prostaglandin $E_{2}$ metabolites were not assessed separately. If, however, prostaglandin $\mathrm{E}_{2}$ synthesis was indeed stimulated, and if it contributed to the unloading effect of enalapril, it was not suppressed in most patients by the low dose of salicylate we used. Published work shows that stimulation of the synthesis of vasodilatory prostaglandins by a converting enzyme inhibitor, if it exists, is restricted mostly to prostaglandin $\mathrm{E}_{2}$ and that it is not observed in all patients. ${ }^{5-7}$

The effect of enalapril on the excretion of renal prostanoids in our study was similar to that found for systemic prostanoids, except that at baseline, contrary to what was found for the systemic prostanoids, excretion of 6ketoprostaglandin $\mathrm{F}_{1 a}$ was much higher than that of thromboxane $B_{2}$. This probably reflects the highly activated state of the reninangiotensin system. ${ }^{12627}$ The mechanism is a specific stimulation of renal prostaglandin $\mathrm{I}_{2}$ synthesis by angiotensin II or angiotensin (1-7) or both. ${ }^{15}$ Renal prostaglandin $I_{2}$ synthesis has been described as a safety mechanism that protects the renal circulation from excessive vasoconstriction by angiotensin II. We found that this mechanism was indeed active in patients with heart failure. Renal prostaglandin $\mathrm{I}_{2}$ synthesis was strongly stimulated and renal thromboxane $A_{2}$ production mildly stimulated by angiotensin II, since after enalapril the excretion of renal thromboxane metabolites was also reduced. The fact that blood pressure fell simultaneously excluded an important contribution of renal prostaglandin $I_{2}$ synthesis to the unloading effect of the converting enzyme inhibitor. Data indicate that the stimulation of prostaglandin $I_{2}$ synthesis is mainly due to angiotensin II as the concentration of angiotensin (1-7), which is derived from angiotensin I, would be expected to increase when conversion of angiotensin I to angiotensin II is blocked by a converting enzyme inhibitor. If stimulation by angiotensin (1-7) were important prostaglandin $\mathrm{I}_{2}$ synthesis would have increased after enalapril.

In our study salicylate inhibited the synthesis of systemic and renal thromboxane $\mathrm{A}_{2}$ and had no significant effect on prostaglandin $I_{2}$ synthesis. As a result, the ratio of prostaglandin $I_{2}$ to thromboxane $A_{2}$ concentration increased. Selective inhibition of the synthesis of thrombogenic thromboxane $A_{2}$ is considered to be the mechanism underlying the protective effect of salicylate in patients with coronary artery disease. ${ }^{3}$ However, the effect of salicylate on thromboxane $B_{2}$ excretion was present only during the first night, after the enalapril effect had waned; daytime excretion of thromboxane $\mathbf{B}_{2}$ and dinorthromboxane $B_{2}$ was not reduced. The apparent absence of effect during the day might be due to pharmacokinetic properties of the salicylate that make the effect trail behind that of enalapril. It is more likely that the effective suppression of thromboxane $B_{2}$ and 
dinorthromboxane $\mathrm{B}_{2}$ excretion during the day by enalapril leaves no opportunity for the salicylate to reduce their excretion further. In the extended study the effect of enalapril lasted for the full 24 hours because the drug accumulated. As a result, enalapril mediated suppression of prostanoid excretion had lasted into the night so suppression of overnight thromboxane $\mathbf{B}_{2}$ excretion by salicylate could no longer be detected. This is in agreement with the conclusion given above that suppression of thromboxane $B_{2}$ excretion by enalapril masks suppression by salicylate.

The same happened with blood pressure and ventricular unloading. During the short term study a significant "de-unloading" effect of salicylate addition was found during the night, when the enalapril effect had waned, but during the day no effect was found on average for the whole group. A significant contribution of enalapril induced prostaglandin $\mathrm{E}_{2}$ synthesis to the blood pressure reduction during the daytime may have been present in at least a few patients, because unloading was completely reversed in three patients, while in the long term study one of the 12 patients showed such a de-unloading effect. Among the others there were a few in whom the unloading was partly but not significantly attenuated. De-unloading, if present, had no appreciable effect on improvement of exercise tolerance or on regression of cardiac mass.

The interaction of enalapril and salicylate seems to be far more complicated than originally thought. We found no evidence in favour of an important de-unloading effect of salicylate. If present, the effect was mild and on average not significant. It did not interfere appreciably with reversal of remodelling of the ventricle or with improvement of exercise tolerance. Significant de-unloading is to be expected only in patients in whom the prostaglandin $E_{2}$ synthesis is significantly stimulated by the converting enzyme inhibitor. Like other bradykinin mediated effects such as coughing, this seems to occur only in a minority of the patients. Moreover, published data suggest that even if the prostaglandin $\mathrm{E}_{2}$ synthesis is stimulated by the converting enzyme inhibitor it will probably not be suppressed by low doses of salicylate. ${ }^{6}$ The chances that addition of salicylate will significantly reduce the benefit of a converting enzyme inhibitor in patients with heart failure are therefore low.

Surprisingly, evidence was found suggesting that the beneficial effect of salicylate on platelet aggregation through inhibition of the thromboxane $A_{2}$ synthesis is shared by the converting enzyme inhibitor. In the studies of left ventricular dysfunction (SOLVD) enalapril reduced mortality in patients with heart failure not only because it delayed progression of heart failure but also, unexpectedly, because it reduced the incidence of reinfarctions by about $20 \% .^{1}$ The mechanism of the reduction in risk of reinfarction was not clear. Risk was not reduced in patients treated with salicylate. Our results suggest that con- verting enzyme inhibitors largely reduce the rate of reinfarction by blocking the synthesis of thromboxane $\mathrm{A}_{2}$ mediated by angiotensin II in patients with a highly activated reninangiotensin system. This implies that for patients with heart failure the addition of salicylate to enalapril, though not harmful, is probably not very beneficial either. We thank Dr F Boomsma from the Department of Internal
Medicine II of the University Hospital Rotterdam for the rapid Medicine II of the University Hospital Rotterdam for the rapid
determinations of angiotensin II concentration; $M r s ~$ determinations of angiotensin II concentration; Mrs $\mathrm{H}$ van der
Veen from the Department of Pulmonology of the University Veen from the Department of Pulmonology of the University
Hospital of Leiden for her help with the exercise tests and the determination of angiotensin converting enzyme activity; and Mr A van Leeuwen from the Department of Obstetrics of the University Hospital of Leiden for determining urinary prostanoid concentrations. We acknowledge Merck Sharp and Dohme for financial support.

1 SOLVD Investigators. Effect of enalapril on survival in patients with reduced left ventricular ejection fractions and congestive heart failure. $N$ Engl $f \mathrm{Med} 1991$; 325:293-302.

2 Cohn JN, Johnson G, Ziesche S, et al. A comparison of enalapril with hydralazine-isosorbide dinitrate in treatment of chronic congestive heart failure. $N$ Engl f Med

3 Antiplatelet Trialists' Collaboration. Collaborative Antiplatelet Trialists' Collaboration. Collaborative
overview of randomised trials of antiplatelet therapy. I. overview of randomised trials of antiplatelet therapy. I.
Prevention of death, myocardial infarction, and stroke by prolonged antiplatelet therapy in various categories of patients. BMF 1994;308:81-106.

4 Aspirin after myocardial infarction [editorial]. Lancet 1980;i:1 172-3.

5 Swartz SL, Williams GH, Hollenberg NK, Levine L, Dluhy RG, Moore TJ. Captopril induced changes in prostaglandin production. $\mathcal{F}$ Clin Invest 1980;65 1257-64.

6 Moore TJ, Crantz FR, Hollenberg NK, et al. Contribution of prostaglandins to the antihypertensive action of captopril in essential hypertension. Hypertension 1981;3: pril in $768-73$.

7 Nishimura H, Kubo S, Ueyama M, Kubota J, Kawamura K. Peripheral hemodynamic effects of captopril in patients with congestive heart failure. Am Heart $\mathcal{f} .1989$; patients with

8 Hall D, Zeitler H, Rudolph W. Counteraction of the vasodilator effects of enalapril by aspirin in severe heart failure. F Am Coll Cardiol 1992;20:1549-55.

9 Düsing R, Scherhag R, Landsberg G, Glänzer K, Kramer HJ. The converting enzyme inhibitor captopril stimulates prostacyclin synthesis in isolated rat aorta. Eur $\mathcal{F}$ Pharmacol 1983;91:501-4.

10 Swartz SL, Williams GH, Hollenberg NK, Moore TJ, Dluhy RG. Converting enzyme inhibition in essential hypertension: the hypotensive response does not reflect only reduced angiotensin II formation. Hypertension 1979;1:106-11.

11 Scharschmidt L, Simonson M, Dunn MJ. Glomerular prostaglandins, angiotensin II and nonsteroidal antinflammatory drugs. Am f Med 1986;81(suppl 2B): inflamm.

12 Shebuski RJ, Aitken JW. Angiotensin II stimulation of renal prostaglandin synthesis elevates circulating prostacyclin in the dog. $₹$ Cardiovasc Pharmacol 1980;2 667-72.

13 Zusman RM, Keiser HR. Prostaglandin biosynthesis by rabbit renomedullary interstitial cells in culture: stimulation by angiotensin II, bradykinin and arginine vasopressin. $\mathcal{F}$ Clin Invest 1977;60:215-23.

14 Fujimura A, Ebihara A. Effect of furosemide on angiotensin II-mediated prostaglandin $\mathrm{I}_{2}$ production in hypertensive subjects. Eur $\mathcal{F}$ Clin Pharmacol 1990;39: 113-5.

15 Benter IF, Diz DI, Ferrario CM. Cardiovascular actions of angiotensin(1-7). Peptides 1993;14:679-84.

$16 \mathrm{Lin}$ L, Nasjletti A. Role of endothelium-derived prostanoid in angiotensin-induced vasoconstriction. Hypertension in angiotensin-ind

17 Noort WA, de Zwart FA, Keirse MJNC. Changes in urinary 6-ketoprostaglandin $F_{1 \alpha}$ excretion during pregnancy and labour. Prostaglandins 1988;35:573-82.

18 Noort WA, de Zwart FA, Keirse MJNC. Increase in urinary thromboxane excretion during pregnancy and labour. Prostaglandins 1987;34:413-21.

19 FitzGerald GA, Pedersen AK, Patrono C. Analysis of prostacyclin and thromboxane $\mathrm{A}_{2}$ biosynthesis in cardiovascular disease [editorial]. Circulation 1983;67:1174-7.

20 Zusman RM. Effects of converting-enzyme inhibitors on the renin-angiotensin-aldosterone, bradykinin, and arachidonic acid-prostaglandin systems: correlation of chemical structure and biologic activity. Am $\mathcal{F}$ Kidney $D i$ 1987;10:13-23.

21 Chai SY, Zhud J, Mendelsohn FAO. Localization of components of the renin-angiotensin system and site of action of inhibitors. Arzneimittelforschung 1993;43: 214-21.

22 Juillerat L, Nussberger J, Ménard J, et al. Determinants of angiotensin II generation during converting enzyme inhibition. Hypertension 1990;16:564-72. 
23 Urata H, Healy B, Stewart RW, Bumpus FM, Husain A. Angiotensin II-forming pathways in normal and failing human hearts. Circ Res 1990;66:883-90.

24 Tan LB, Jalil JE, Pick R, Janicki JS, Weber KT. Cardiac myocyte necrosis induced by angiotensin II. Circ Res 1991;69:1185-95.

25 Schlondorff D, Singhal P, Hassid A, Satriano JA, DeCandido $S$. Relationship of GTP-binding proteins, phospholipase $\mathrm{C}$, and Prostaglandin $\mathrm{E}_{2}$ synthesis in rat glomerular mesangial cells. Am f Physiol 1989;256: F171-8.

26 Packer M, Lee WH, Kessler PD. Preservation of glomerular filtration rate in human heart failure by activation of the renin-angiotensin system. Circulation 1986;74: 766-74.

27 Schlondorff D, Ardaillou R. Prostaglandins and other arachidonic acid metabolites in the kidney. Kidney Int 1986;29:108-15.

\title{
SHORT CASES IN CARDIOLOGY
}

\section{Leiomyosarcoma in the right atrium and occluding the inferior vena cava}

\author{
Peter Wilmshurst
}

Royal Infirmary, Huddersfield P Wilmshurst

Correspondence to: Dr P T Wilmshurst, Royal Infirmary, Huddersfield HD3 3EA.

Accepted for publication 27 September 1994
The radiographic image (figure) shows a tumour the size and shape of an hen's egg in the right atrium, outlined by contrast injection in the superior vena cava, that was found in a 50 year old woman who presented with fatigue, jaundice, oedema, and ascites. Venous distension was apparent, particularly in the lower half of the body. She was in sinus rhythm with a normal cardiac impulse and no murmurs. The liver was enlarged but not pulsatile. Ultrasound examination of the abdomen showed a tumour at the hilum of

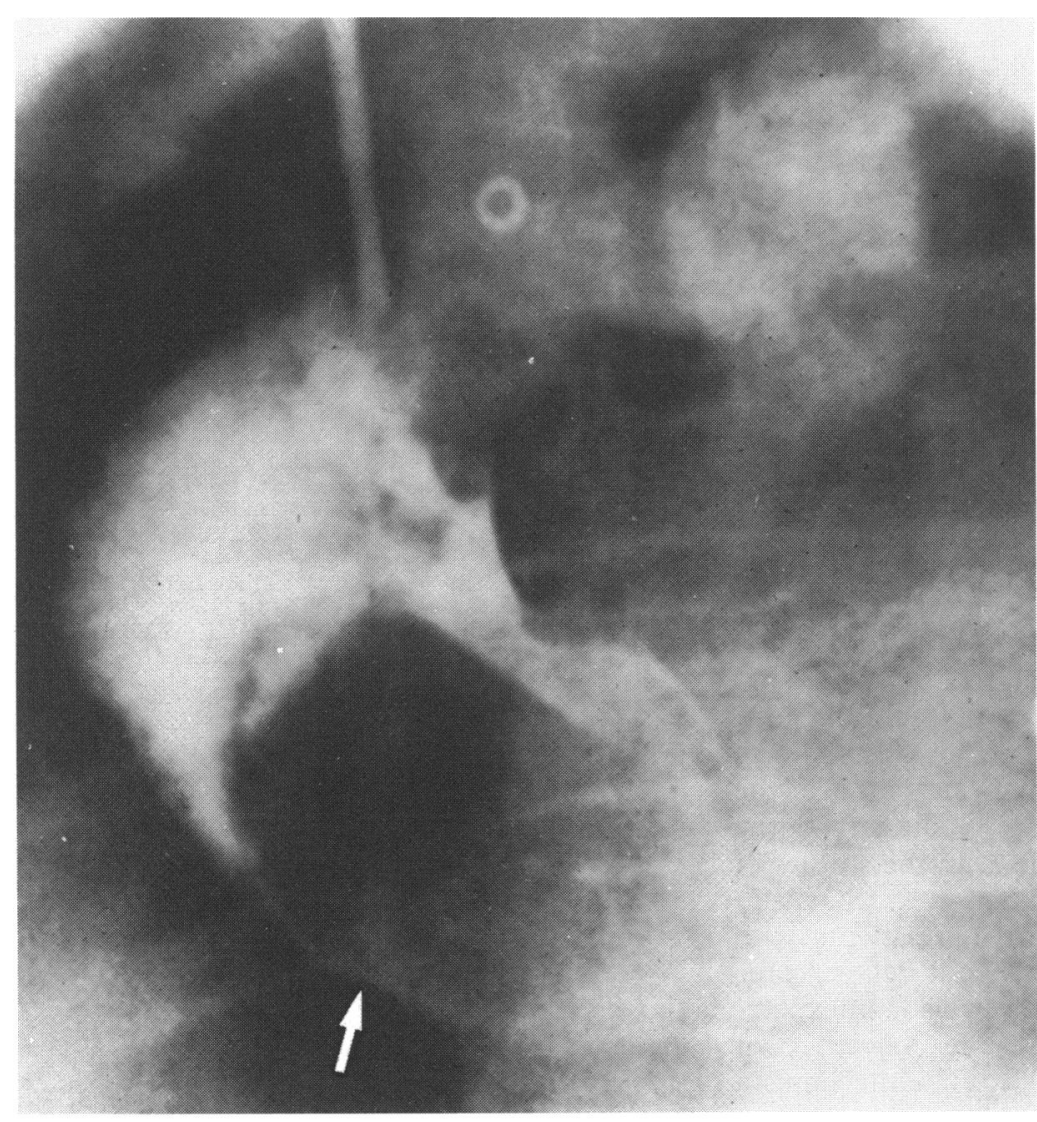

Right atrial leiomyosarcoma, arrow. the liver with total obstruction of the inferior vena cava. Venography confirmed the obstruction with contrast draining to the right atrium via the azygos system.

A biopsy specimen of the right atrial tumour was taken via the right internal jugular vein using a Cordis bioptome (7 French gauge). During biopsy the tumour felt much harder than normal cardiac tissue. Histological examination showed that the tumour was a leiomyosarcoma. It was thought to have invaded the right atrium rather than have originated there. Despite treatment the patient died within six months of presentation.

Masses in the right atrium may be thrombus (arising in situ or embolic), rarer types of emboli, massive vegetations (especially in fungal endocarditis), or tumours. The commonest variety of cardiac tumour is a benign myxoma. In this case, the ultrasound scan suggested that the mass was a malignant tumour invading the right atrium from the inferior vena cava. A histological diagnosis was considered necessary to confirm the diagnosis of malignancy (because some benign tumours, such as leiomyomatosis, ${ }^{1}$ can grow into the right atrium from the inferior vena cava) and to determine what treatment was appropriate. In this case the tumour was a relatively rare solid tumour, a leiomyosarcoma arising in the vena cava. There are about 20 reported cases. ${ }^{2}$ Other malignant tumours that can invade the atrium from the lumen of the vena cava include renal adenocarcinomas and hepatomas. Before surgical removal of a right atrial mass is attempted, it is advisable to visualise the vena cava by ultrasound or contrast radiography to exclude such invasion.

1 Marcus SG, Krauss T, Freedberg RS, Culliford AT, Weinreich DJ, Kronzon I. Pulmonary embolectomy for intravenous uterine leiomyomatosis. Am Heart $f$ intravenous uterine

2 Thompson MM, Graham TR, Bolia AA, Firmin RK, Bell PR. Intrahepatic leiomyosarcoma of the inferior vena cava with extension into the right atrium. Eur $f$ Vasc Surg 1993;7:204-7. 